\title{
The Research and Design on Autonomous Navigation Water Quality Monitoring Ship
}

\author{
Jiaji $\mathrm{Yu}^{1, \mathrm{a}}$, Jiabin $\mathrm{Yu}^{1, \mathrm{~b}}$, Cheng Wang ${ }^{1, \mathrm{c}}$, Xiaoyi Wang ${ }^{1, \mathrm{~d}}$, Jiping $\mathrm{Xu}^{1, \mathrm{e}}$, \\ Li Wang ${ }^{1, f}$ and Huiyan Zhang ${ }^{1, g}$
}

Beijing Key Laboratory of Big Data Technology for Food Safety, School of Computer and Information Engineering, Beijing Technology and Business University, Beijing, 10048, China

Nice_jiaji@126.com, ${ }^{b}$ yujiabin@th.btbu.edu.cn, ${ }^{d}$ sdwangxy@163.com.com, exujiping@139.com, 'xiaolizi1983@hotmail.com, ${ }^{9}$ zhanghuiyan369@126.com,

\begin{abstract}
Keywords: autonomous navigation, water quality monitoring, obstacle avoidance, remote monitoring
\end{abstract}

Abstract: At present, river and lake water quality monitoring method is single and the monitoring range is limited, then the paper designs a river and lake water quality monitoring ship based on the autonomous navigation technique, including forward and reverse power module, battery power module, autonomous navigation module, obstacle avoidance module, automatic water taking module, water quality monitoring module and wireless transmission module. Use GPS and acceleration sensor to realize autonomous navigation when monitoring ship is subject to scheduled path. Use onboard multi-parameters water environment monitor and automatic water taking by mechanical arm to automatically gain water sample and real-time monitoring of water quality. At the same time, it can transfers to the upper computer by $3 \mathrm{G}$ network. On software, it designs handheld mobile device based on Android platform and remote monitoring software platform based on PC to receive water quality parameters sent by monitoring ship and path information for remote monitoring work status of water quality monitoring ship and the change of water quality. The autonomous monitoring ship promotes water quality monitoring effectiveness and reduces monitoring cost, at the same time, it gives real-time monitoring to water quality and makes accurate regulation to provide favorable technology support for river and lake water pollution monitoring and prevention.

\section{Introduction}

Lake and reservoir as the direct source of human water using, are the important foundation of social and economic sustainable development. With the rapid development of economic, the demand and influence of industrial and agricultural production and the life process to water resource is becoming more and more big, $95 \%$ of the surface water source in our country have been polluted in varying degrees ${ }^{[1,2]}$, the eutrophication degree of Lake and reservoir is becoming more and more serious. At present, the eutrophic lakes and reservoirs are respectively $69.8 \%$ and $41.95 \%$ of the total ${ }^{[3]}$, which is a wake-up call for mankind. Although people have raised the alert, but the water environment continues to deteriorate further, so it is urgent to strengthen management of water quality monitoring and water pollution prevention work In our country.

At present, there is still a big flaw in the existing water quality monitoring system that the number and coverage of water quality monitoring system are insufficient ${ }^{[4,5]}$. Through the survey we can found that a large part of the reason is that the monitoring tool is too single. At present, most of the water quality monitoring task is completed by the fixed monitoring stations all around the water area, but monitoring scope of the water quality monitoring system composed of fixed monitoring point is limited because every monitoring point is fixed. Therefore, in order to cover the entire scope of water area, we must install a certain number of fixed point fitted with a variety of expensive water quality monitoring sensors at the same time. If a mobile monitoring point can be substituted for the original fixed point, and the route is under control, a mobile monitoring can cover the area of the original fixed monitoring stations ${ }^{[6-8]}$. 
Against this background, the paper designs a water quality monitoring ship which can carry out autonomous navigation. including forward and reverse power module, battery power module, autonomous navigation module, obstacle avoidance module, automatic water taking module and wireless transmission module. Use GPS and acceleration sensor, Combining with the Angle sensor and complex control algorithm, to realize autonomous navigation when monitoring ship is subject to scheduled path. At the same time, Using onboard multi-parameters water environment monitor to automatically gain water sample and real-time monitoring of water quality.On software, this paper designs handheld mobile device based on Android platform and remote monitoring software platform based on PC to receive water quality parameters sent by monitoring ship and path information for remote monitoring work status of water quality monitoring ship and the change of water quality. The motion system of this monitoring ship is stable, meanwhile, it promotes water quality monitoring effectiveness and reduces monitoring cost. So it can boost Lake and reservoir water environment pollution prevention ability and improve the level of water environment management and operation.

\section{The overall framework of monitoring ship}

The overall architecture of autonomous navigation water quality monitoring ship is mainly divided into two parts: autonomous navigation water quality monitoring section、 upper computer monitoring software section. The system framework of the autonomous navigation water quality monitoring ship is shown in Fig.1.

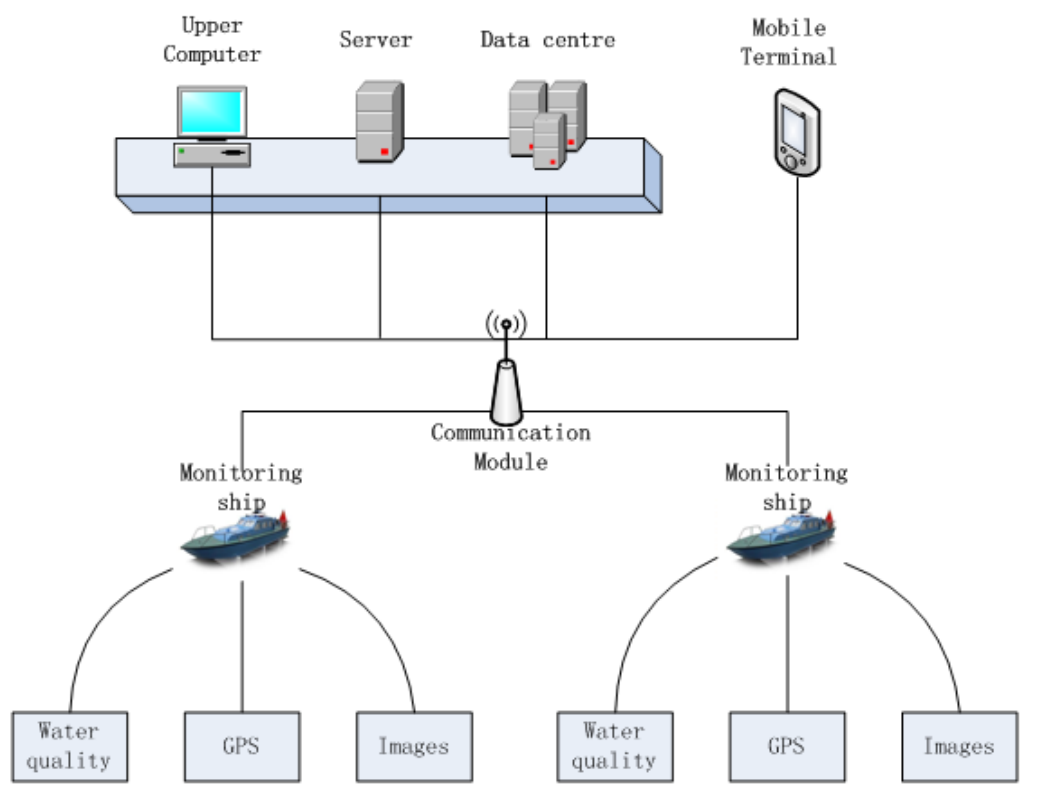

Fig.1 The system framework of the autonomous navigation water quality monitoring ship

Autonomous navigation water quality monitoring ship works in lake area all the time, including forward and reverse power module controlled by relay and the gear transmission device、 battery power module、 navigation system combined with GPS and acceleration sensor、obstacle avoidance system 、 automatic water taking system with mechanical arm、 water quality monitoring module and wireless transmission module. Use GPS and acceleration sensor to realize autonomous navigation when monitoring ship is subject to scheduled path. Use angle sensor、 brushless motor and toothed gearing to control the monitoring ship to go forward and reverse precisely. Use ultrasonic sensors, infrared and temperature sensor to avoid obstacle. Meanwhile, the monitoring ship is able to take water automatically with mechanical arm and use onboard multi-parameters water environment monitor to automatically gain water sample and real-time monitoring of water quality. At the same time, it can transfers to the upper computer by $3 \mathrm{G}$ network. 
Upper computer monitoring software include the handheld mobile terminal and the remote monitoring software platform, the former is based on mobile phone android platform and it is mainly used to receive the real-time water quality parameter information from monitoring ship and some information such as location and mileage of the ship through $3 \mathrm{~g}$ wireless communication network .Remote monitoring software platform is mainly based on the PC, it can evaluate the water quality of the monitoring area through the default model, and it can also record steering Angle, battery dosage and the working state of various sensors of the monitoring ship. Meanwhile, the software can change the cruise route to select sample point according to the actual situation, by changing coordinates of the set point. At the same time, platform control section is equipped with a manual control and automatic control in two ways, so that we can manually control the monitoring ship to go forward, backward and swerve. This setting greatly ensure the ship safety while realizing the real-time monitoring of water quality.

\section{Hardware integrated design of the monitoring ship}

The autonomous navigation water quality monitoring ship includes the control circuit, the monitoring of the ship motion control, the obstacle avoidance section, the battery power supply section, the automatic water taking system with mechanical arm, and the online water environment monitoring system.

\section{Control circuit design}

Part of the Control circuit system is shown in Fig. 2.

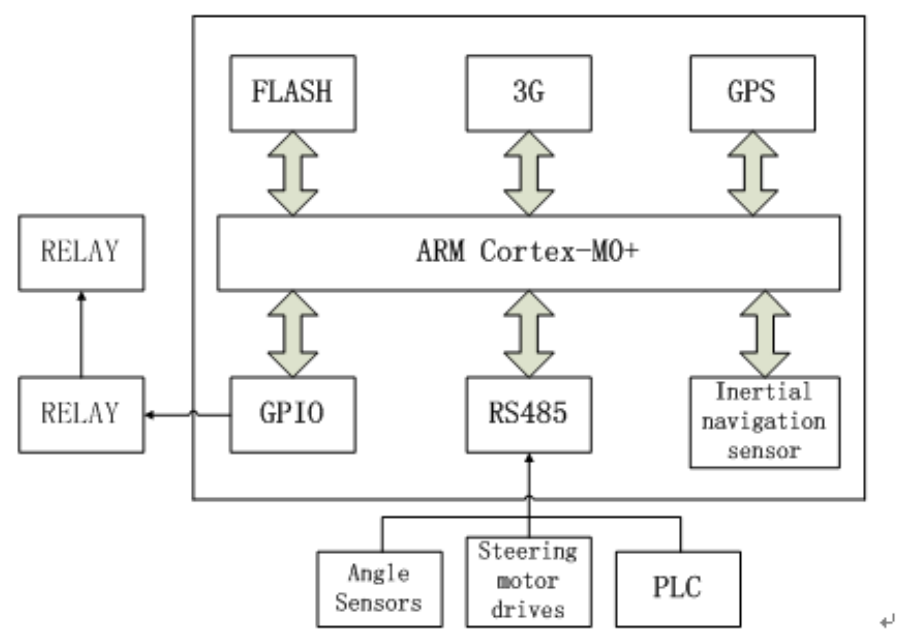

Fig.2 The structure of control circuit system

Master controller MCU uses ARM Cortex-M0+ series processor. The external FLASH memory is mainly used for the storage of attitude information, steering angle information and the states information of the ship. GPS module, inertial navigation sensor are mainly used for accurate acquisition of the ship's location information. $3 \mathrm{G}$ module is mainly used for data communication with the remote control terminal and the remote monitoring software platform. The GPIO interface can control forward, backward and gear shift of the cruise ship through connecting with relays. The RS485 input interface is mainly connected with the angle sensor, the steering motor driver and the PLC, in order to achieve precise control of the steering motor action and control information of the mechanical arm water taking device.

Design of motion control system

Design of the motion control system for autonomous monitoring ship is shown in Fig. 3. 


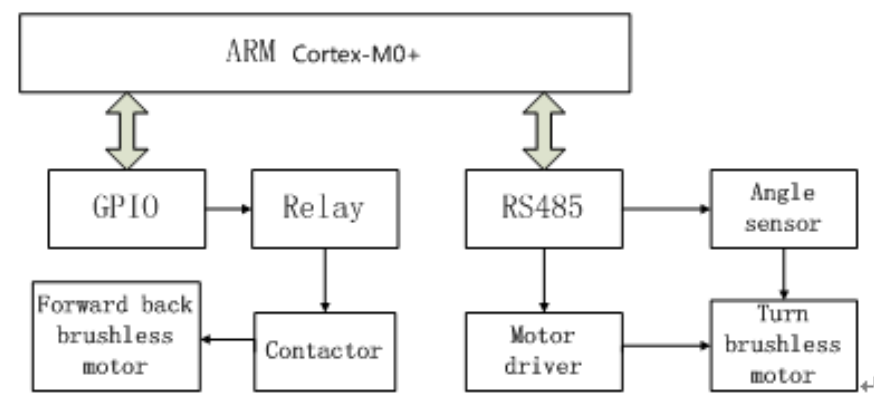

Fig.3 The design framework of motion control system

The motion control system of water quality monitoring ship is composed of relay, contactor, angle sensor, motor driver and two brushless motor. First, through changing the level of GPIO control small relay action, thereby driving the contactor action and then control the speed and steering of forward and backward motor. Second, the serial port RS485receives the real-time angle sensor information, and then control the motor driver to drive the turning brushless motor action.

In terms of the problems that the monitoring ship is supplied by DC power and its power is too big, which means using relays alone couldn't achieve the motor speed control, therefore, it uses the relays to control contactors. As a result, it is safer to make the switch and reverse. In order to make precise control of the steering angle of water quality monitoring ship, it uses the closed-loop feedback system of angle sensor and motor driving and PID algorithm which makes monitoring ship steer more accurately.

\section{Obstacle avoidance system}

The sensors of obstacle avoidance system of the monitoring ship include follows: the ultrasonic sensor, the infrared Sensor and the temperature sensor. In order to realize these functions, such as auto-control, obstacle avoidance and automatic berths and so on, the obstacle avoidance system with GPS and the inertial sensor of the navigation system are applied to the system.

Two ultrasonic ranging sensors, one infrared sensor and one temperature sensor are installed in the front and back of the water quality monitoring ship, which can detect the surface situation of the lake surrounding obstacles. Ultrasonic sensor, converted the electrical signals, using inverse piezoelectric effect, to ultrasonic wave that radiates outward. And transform mechanical vibration back to electrical signals utilizing the piezoelectric effect. Ultrasonic is a kind of sound wave. The speed of its transmission relates to temperature. Thus it is necessary to have a temperature sensor monitoring the water temperature and adjusting the speed by temperature compensation. The formula of speed calculation is shown as $\mathrm{Eg}(1)$.

$\mathrm{V}=331.45+0.607 \mathrm{~T}$

The speed can be calculation through the outcome of the temperature sensor. And $t$ indicates the difference between time detected in the sensor of sending and receiving the ultrasonic. Accordingly, $\mathrm{s}$ indicating the distance to the barrier can be calculated as Eg (2).

$\mathrm{S}=\mathrm{V} * \Delta \mathrm{t} / 2$

Because of the weakness of capacity to detect the barriers in the short distance, infrared sensor is introduced to overcome the shortage. This whole obstacle avoidance system can avoid barrier and ensure the safety of a water quality monitoring ship in either short or long distance.

\section{Battery power syetem}

In order to make the monitoring ship work for a long time, we use power supply method of solar energy with accumulator. When sunshine is sufficient, solar energy is utilized for power supply and accumulator is charged. When it is cloudy, the accumulator is used and equipment with maximum power consumption is switched off automatically to ensure the ship in long time continuous work. Considering that direct current motor is $12 \mathrm{~V}$ power supply, while main control panel ARM and other 
devices are $5 \mathrm{~V}$ power supply, duplicate supply is used. Electric isolation is between power suppliers to guarantee normal operation of devices.

\section{Automatic water taking system with mechanical arm}

In order to exactly control mechanical arm to make fix-point sampling for lake, PLC is used to control mechanical arm. As PLC has automatic hardware error detecting function and inhibits external interference sources' influence. Through controlling motor action in PLC control arm, realize exact capture for water sample. The main control machine ARM is connected with PLC by RS485, receiving real-time information from mechanical arm to control PLC and complete water sampling collection.

\section{Onboard multi-parameters water environment monitor}

Onboard multi-parameters water environment monitor can realize the real-time data acquisition function through the built-in sensor probe and online water quality information acquisition module. It can also monitor many indicators at the same time, such as temperature、ph、Dissolved Oxygen、 Conductivity、Chlorophyll、Salinity、Redox potential、Total dissolved solid Phycoerthrin、 Phycocyanin. The system receives the data collected from sensor by using serial port communication technology and store the data in database files, so that the system can queries, call and draw the curve of the real-time and historical data conveniently. Multi-parameters water environment monitor is shown as Fig.4.
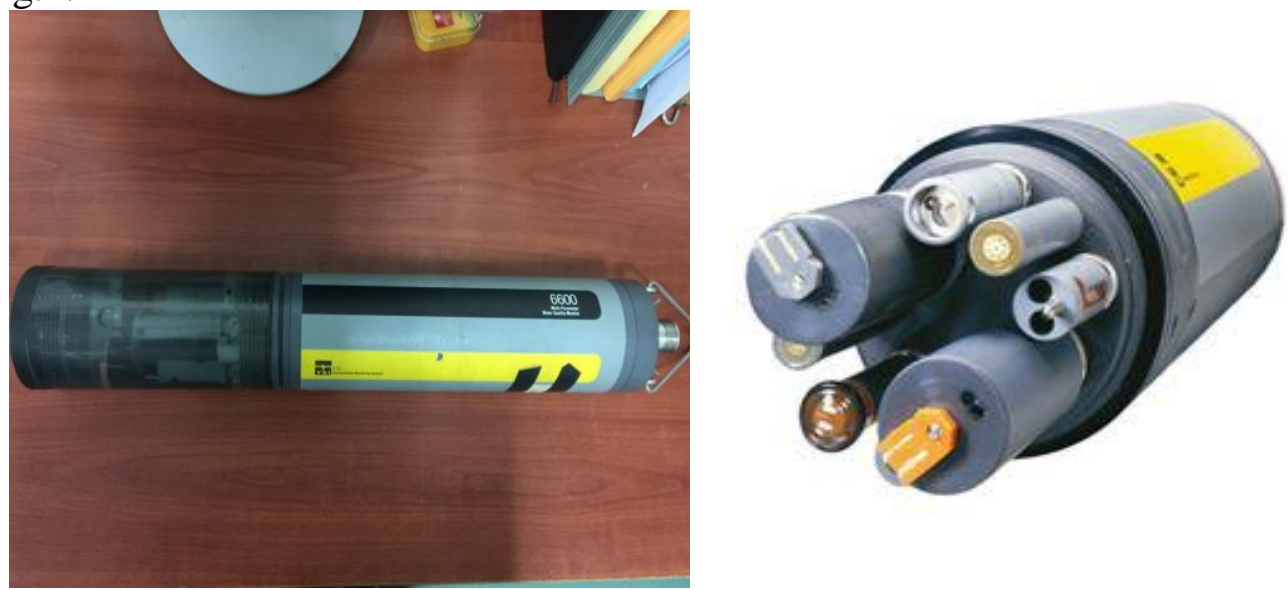

Fig.4 Onboard multi-parameters water environment monitor

\section{The integrated management software platform of monitoring ship}

\section{Software design}

The software design uses the modular design concept, which means the different system function is packaged into many subsystems. The architecture of upper control system and monitoring software are shown in Fig.5. 


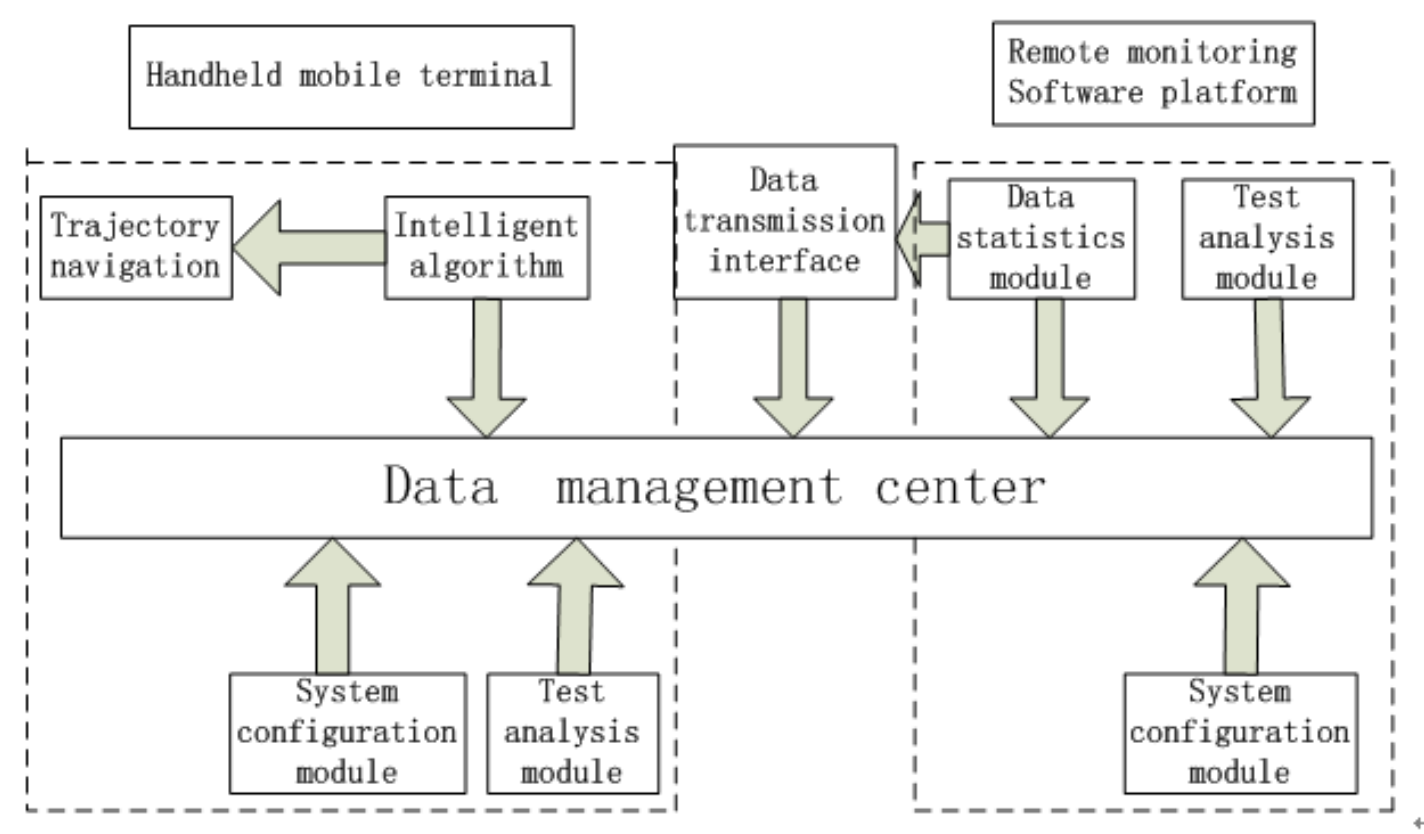

Fig. 5 The design of integrated management software platform of monitoring ship

As shown in the picture, the monitoring ship will transmitted the information that the position of monitoring ship, the mileage of monitoring ship and the water quality information collected by multi parameter water quality monitor on the ship to the host database through the wireless transmission module which is the $3 \mathrm{G}$ communication network. Then, the data will be used by handle mobile terminal and remote monitoring software through data transmission interface. In this way, water quality assessment will be established and monitoring ship operating state will be monitored distantly.

\section{Handheld mobile terminal design}

Handheld mobile terminals, mainly based on Android platform of mobile phones, can receive real-time data of the location of monitoring ship, the travel path of monitoring ship and the quality of water provided by monitoring ship, etc. This software is mainly used to display the parameter of the water quality and the running state of the monitoring ship. At the same time, it will compare the water quality monitoring ship's actual operating position and theoretical position by image technology, perform real time operation information of the robot arm, show the navigation algorithm and the error of manipulator operation more clearly. Also, it corrects the information, playing feedback effect on water quality monitoring ship.

\section{The design of remote monitoring software platform}

Remote monitoring software platform is mainly based on PC machine. Besides the GIS display, the display of water quality monitoring ship running state, and the display of water quality parameters data, it can also be used to evaluate the water quality of the water according to the collected data through the default model, and can also record the steering angle, battery quantity and various sensors working condition. At the same time, it can modify the monitoring ship's cruise line by changing the setting point renewing sampling points. In addition, the software can also immediately have respond and alarm to the aberrant results obtained from the analysis of the data collected by monitoring ship. The screenshot of software is shown in Fig.6. 


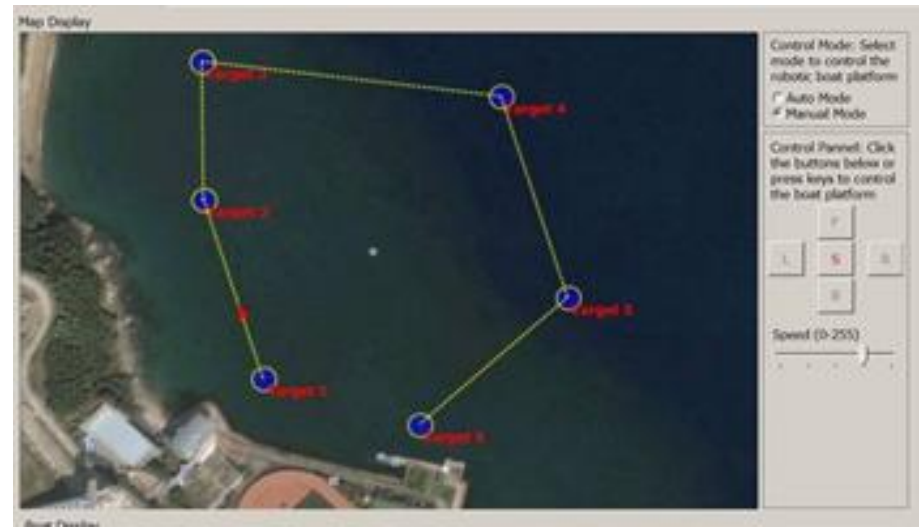

Fig.6 Screenshot of remote monitoring software

\section{Experimental verification}

\section{Autonomous navigation system test}

In order to test whether the monitoring ship can realize autonomous navigation according to the functional design, we add a experimental verification link in Beijng Yu yuantan Park. Firstly, set the cruise path of the monitoring ship and extract the coordinates of four set point as a reference, then record the point coordinates of the actual route that monitoring ship passes through the upper monitoring software. Finally, make a comparative analysis between latitude and longitude of the set point and the point that monitoring ship actually arrival. Take the average value of many experiments. The data is shown in Table 1.

Table 1 Autonomous navigation system test data

\begin{tabular}{|c|c|c|c|}
\hline Serial Number & $\begin{array}{l}\text { Longitude and latitude of } \\
\text { the set point }\end{array}$ & $\begin{array}{l}\text { Longitude and latitude } \\
\text { of the actual point }\end{array}$ & Error analysis \\
\hline \multirow{2}{*}{1} & $116^{\circ} 19^{\prime} 26.44^{\prime \prime}$ & $116^{\circ} 19^{\prime} 26.39^{\prime \prime}$ & \multirow{2}{*}{ Little error } \\
\hline & $39^{\circ} 55^{\prime} 15.57^{\prime \prime}$ & $39^{\circ} 55^{\prime} 15.55^{\prime \prime}$ & \\
\hline \multirow{2}{*}{2} & $116^{\circ} 19^{\prime} 29.04^{\prime \prime}$ & $116^{\circ} 19^{\prime} 29.10^{\prime \prime}$ & \multirow{2}{*}{ Little error } \\
\hline & $39^{\circ} 55^{\prime} 16.36^{\prime \prime}$ & $39^{\circ} 55^{\prime} 16.38^{\prime \prime}$ & \\
\hline \multirow{2}{*}{3} & $116^{\circ} 19^{\prime} 32.11^{\prime,}$ & $116^{\circ} 19^{\prime} 32.15^{\prime}$ & \multirow{2}{*}{ Little error } \\
\hline & $39^{\circ} 55^{\prime} 17.01^{\prime \prime}$ & $39^{\circ} 55^{\prime} 17.06^{\prime \prime}$ & \\
\hline \multirow{2}{*}{4} & $116^{\circ} 19^{\prime} 33.63^{\prime \prime}$ & $116^{\circ} 19^{\prime} 33.70^{\prime \prime}$ & \multirow{2}{*}{ Little error } \\
\hline & $39^{\circ} 55^{\prime} 17.55^{\prime \prime}$ & $39^{\circ} 55^{\prime} 17.50^{\prime \prime}$ & \\
\hline
\end{tabular}




\section{Test result analysis}

After many experiments, we can find that there is little error between the longitude and latitude of the point of default route and the actual route in the process of driving by comparing the coordinate data. It proves that the actual route of monitoring ship is in accordance with the default cruise route and the autonomous navigation system can work properly according to the functional design.

\section{Conclusions}

This paper designs a autonomous navigation water quality monitoring ship, Using GPS and acceleration sensor, Combining with the Angle sensor and complex control algorithm ,to realize autonomous navigation when monitoring ship is subject to scheduled path. At the same time, Using onboard multi-parameters water environment monitor to automatically gain water sample and real-time monitoring of water quality. On software, this paper designs handheld mobile device based on Android platform and remote monitoring software platform based on PC to receive water quality parameters sent by monitoring ship and the work status of water quality monitoring ship to realize the continuous real-time monitoring of the lake and reservoir water environment. Compared with the fixed point, the monitoring ship saves more energy and covers a wider area. It promotes water quality monitoring effectiveness and reduces monitoring cost and provides favorable technology support for river and lake water pollution monitoring and prevention at the same time.

\section{Acknowledgments}

This study is supported by National Natural Science Foundation of China (No.51179002); Beijing Municipal Education Commission science and technology plan key projects(No.KZ201510011011); Those supports are gratefully acknowledged.

\section{References}

[1] Zhang Ying. Current situation of surface water quality monitoring in China[J]. Science \& Technology Information, 2011, 26 (1):59-59.

[2] Gao Juan, Hua Luo, Hua Liping, Zhang Zhenxian, Yin Xunxiao, et al. Analysis of Surface Water Quality Monitoring Condition and Its Countermeasures[J].Journal of Capital Normal University(Natural Science Edition), 2006, 27(1):75-80.

[3] Fu Longliang, Chen Xiaobin, Lin Qunfu. Unmanned water environment monitoring ship[J]. China New Technologies and Products, 2014, (3) :169-169.

[4] Wang Weixing, Gao Yilong, Chen Binbin, Chen Jiasen, Zhu Zhibin,et al. Unmanned automatic navigation monitoring ship[J]. Information Technology and Informatization, 2014,5:36-38.

[5] Zhu Xiaowei, Huan Juan, Liu Jianfei, et al. Design of intelligent water quality monitoring ship[J]. Popular Science \& Technology, 2014, 11:25-26.

[6] Mend Xianbao, Huan Jiayi, Xie Qiuho, Chen Wanyun, et al. Online Monitoring Equipment for Aquaculture Based on Unmanned Automatic Cruise Boat $[\mathrm{J}]$. Transactions of the Chinese Society for Agricultural Machinery, 2015, 03(3).

[7] Jin Yinglian, Wang Binrui, Yan Tianhong. Motion Control System Design of Autonomous Monitoring Ship for Lake Water Environment[J]. Computer Engineering, 2012,38(22):240-243.

[8] Huang Yanyan, Jin Yinglian, Fang Shuiguang, Wang Binru, et al. GPS Navigation Design of Autonomous Monitoring Ship in Lake Environment[J]. Computer Engineering,2012,38(8). 
